\title{
Correction to: Human Development and Net Migration: The Ghanaian Experience
}

\section{Anthony Amoah ${ }^{1}$ D $\cdot$ Carlos Tetteh ${ }^{2} \cdot$ Kofi Korle $^{3} \cdot$ Samuel Howard Quartey $^{4}$}

Published online: 24 August 2021

(c) Springer Nature B.V. 2021

\section{Correction to: Journal of International Migration and Integration https://doi.org/10.1007/s12134-021-00874-6}

\section{Complaint:}

The original version of the article unfortunately contained an error in the authors' affiliations.

Additional numerical data has inadvertently been added to all authors' names hence affiliating them to institutions they don't belong to. The correct authors' names are shown above with footnotes showing their correct affiliations.

The original article has been corrected.

Publisher's Note Springer Nature remains neutral with regard to jurisdictional claims in published maps and institutional affiliations.

The original article can be found online at https://doi.org/10.1007/s12134-021-00874-6.

Anthony Amoah

aamoah@uesd.edu.gh

1 School of Sustainable Development, University of Environment and Sustainable Development, Somanya, Ghana

2 Department of Economics, University of Ghana, Legon, Accra, Ghana

3 Department of Economics, Central University, Accra, Ghana

4 Department of Adult Education and HR Studies, School of Continuing and Distance Education, College of Education, University of Ghana, Legon, Accra, Ghana 